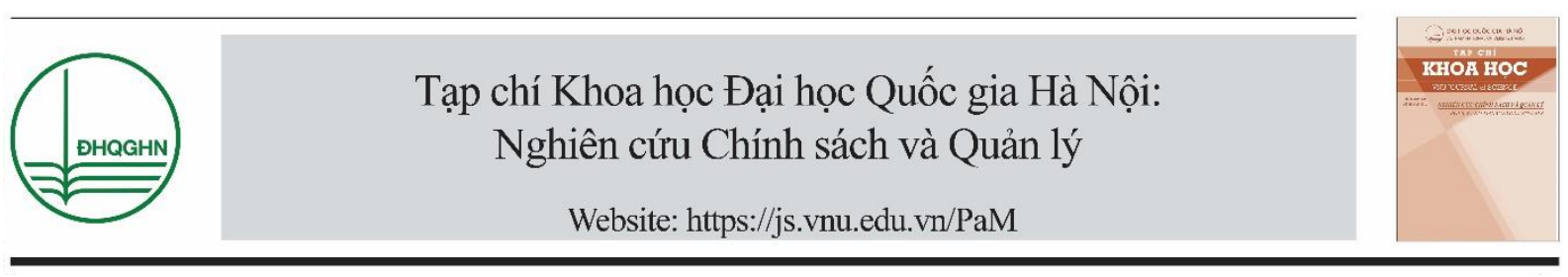

\title{
Chảy chất xám tại chỗ trong bối cảnh cuộc cách mạng công nghiệp 4.0: Một số vấn đề đặt ra
}

\author{
Đào Thanh Trường*, Nguyễn Thị Ngọc Anh \\ Truờng Đại học Khoa học Xã hội và Nhân văn, ĐHQGHN, 336 Nguyễn Trãi, Hà Nội, Việt Nam
}

Nhận ngày 28 tháng 9 năm 2018, Chấp nhận đăng ngày 30 tháng 9 năm 2018

\begin{abstract}
Tóm tắt: Chảy chất xám là một vấn đề không mới nhưng luôn là vấn đề nóng của các quốc gia. Đặc biệt, trong bối cảnh cuộc cách mạng công nghiệp 4.0 thì vấn đề chảy chất xám càng được quan tâm nghiên cứu. Chảy chất xám là vấn đề phức tạp, gây ra nhiều tranh luận khi được nhắc đến bởi những tác động âm tính, dương tính và ngoại biên của nó gây ra. Xét theo quan điểm truyền thống về chảy chất xám thì đây là một hiện tượng nguy hại, chỉ sự di động xã hội kèm di cư của nguồn nhân lực chất lượng cao, tuy nhiên, trong bối cảnh mới, hiện tượng này lại có những biểu hiện khác ở dạng tiềm ẩn và cần các nhà nghiên cứu, các nhà quản lý lưu tâm hơn. Bài viết của tác giả xoay quanh về chảy chất xám theo quan điểm truyền thống và quan điểm 4.0. Theo đó, tác giả phân tích những yếu tố tác động đến tình trạng chảy chất xám tại chỗ và đưa ra những điểm mà Việt Nam cần lưu ý khi hoạch định chính sách quản lý di động nguồn nhân lực KH\&CN chất lượng cao trong bối cảnh mới.
\end{abstract}

Tù khóa: chảy chất xám, cách mạng công nghiệp 4.0, di động xã hội

\section{Dẫn nhập}

Chảy chất xám không còn là câu chuyện của riêng quốc gia nào, nó đã trở thành một vấn đề chung của thế giới. Câu chuyện về chảy chất xám với thuật ngữ "brain drain" được sử dụng bắt đầu từ năm 1963, khi Hiệp hội hoàng gia Anh thấy sự suy giảm chất xám của các nhà khoa học từ Anh sang Mỹ, gây nguy hiểm cho nền kinh tế của Anh. Sau đó, thuật ngữ này được sử dụng rộng rãi để mô tả sự di chuyển của các chuyên gia, nhà khoa học từ các nước thứ ba [1]. Hay như ở Nga, chảy chất xám

\footnotetext{
* Tác giả liên hệ. ĐT.: 84-913016429.

Email: truongkhql@gmail.com

https://doi.org/10.25073/2588-1116/vnupam.4155
}

còn được gọi thêm bằng các tên khác nhau như: đánh cắp chất xám (brain theft) hay câu chất xám (brain bait). Thực chất đây không phải là vấn đề mới, đặc biệt vào cuối thế kỷ 17, đầu thế kỷ 18 khi Peter Đại đế thực hiện chính sách thu hút các chuyên gia có tài năng làm việc tại Nga. Vào đầu thế kỷ 20, trong cuốn "Tư bản và Công nhân", V.I. Lenin đã đưa ra kết luận rằng "nước Nga ngày càng bị lùi lại phía sau, đưa cho ngoại quốc nhũung người làm việc tốt nhất, trong khi Mỹ ngày càng tiến nhanh hơn, thu hủt nhũng phần dân số năng động và tài năng nhất của thế giới”'[2]. Mặc dù được viết năm 1913 nhưng đến nay, lời nhận định đó vẫn còn có giá trị. 
Đó là câu chuyện của những thế kỷ trước, với sự thay đồi liên tục và mạnh mẽ của thế giới, vấn đề này đã có sự đổi khác cả trên chiều cạnh lý luận và thực tiễn.

\section{Quan điểm về chảy chất xám: truyền thống và 4.0}

\subsection{Chảy chất xám theo quan điểm truyền thống}

Trong tất cả các nguồn lực để tạo lên sự phát triển của một quốc gia thì chất xám (nguồn nhân lực chất lượng cao) luôn là yếu tố tiên quyết, được đầu tư và cũng được "săn đón" nhiều nhất.

Thuật ngữ "chảy chất xám" được sử dụng thông qua một loạt từ tiếng Anh như "brain drain", "human capital flight". Thông thường, trong các công trình nghiên cứu, bài báo tại Việt Nam, thuật ngữ này được dịch và sử dụng phổ biến với cụm từ "chảy máu chất xám". Tuy nhiên, tác giả nhận thấy "brain drain" không nhắc đến "máu" trong cả từ và nghĩa nên trong bài nghiên cứu này, tác giả sử dụng cụm từ "chảy chất xám" theo đúng nghĩa của nó.

Theo định nghĩa của Merriam-Webster thì "chảy chất xám - brain drain" là thuật ngữ dùng để chỉ "sự ra đi của những người được đào tạo, những chuyên gia từ một quốc gia, một khu vực, một lĩnh vực kinh tế đến những nơi có điều kiện về thu nhập và cuộc sống tốt hơn" [3].

Theo Worldatlas, chảy chất xám dùng để chỉ "hiện tượng khi những công dân có kỹ năng rời khỏi tổ quốc. Nhìn chung, chảy chất xám liên quan đến sự di cư giữa các vùng địa lý" [4].

Theo từ điển Collins English thì chảy chất xám được định nghĩa là "sự di cư của những nhà khoa học, nhà công nghệ, nhà nghiên cứu,.. để có những điều kiện, trang thiết bị và thu nhập tốt hơn" [5].

Theo nghĩa chung nhất, "chảy chất xám" là hiện tượng mà nguồn nhân lực chất lượng cao di chuyển sang một quốc gia khác và cống hiến trí lực cho quốc gia đó. Nói chung, theo những định nghĩa ở trên thì chảy chất xám luôn luôn gắn liền với việc di chuyển của nhân lực chất lương cao từ khu vực này đến khu vực khác.

Xét trên quan điểm "cung - cầu" của kinh tế học thì chảy chất xám là hiện tượng tất yếu và hợp lý. Vấn đề này xảy ra khi nhân lực chất lượng cao có nhu cầu di động đến những vùng miền/quốc gia có điều kiện về kinh tế, xã hội, môi trường tốt và phù hợp hơn. Hơn hết, chính các quốc gia đó cũng có nhu cầu và khả năng thu hút, giữ chân những nhân lực chất lượng cao đó. Theo định luật bảo toàn và chuyển hóa năng lượng của vật lý học thì nếu coi "chất xám" là một dạng năng lượng đặc biệt thì chúng ta cũng có một định luật "phái sinh" khác: chât xám không tư nhiên sinh ra mà cũng không tự nhiên mất đi, nó chỉ chuyển hóa từ dạng này sang dạng khác hoặc từ quốc gia này sang quốc gia khác. Xét trong một hệ kín (thế giới) thì tổng lượng chất xám được bảo toàn.

Chảy chất xám được chia thành nhiều cấp độ khác nhau [6]:

+ Cấp độ địa lý: khi chuyên gia chuyển từ một quốc gia/một vùng sang một quốc gia khác có điều kiện sống tốt hơn và nhiều cơ hội phát triển hơn. Việc di chuyển này có thể xuất phát từ những bất ổn về chính trị, điều kiện sống không tốt,...

+ Cấp độ tổ chức: là sự di chuyển của các nhân viên có kỹ năng từ một công ty có thể là do sự bất ổn của tổ chức hoặc thiếu cơ hội phát triển,...

+ Cấp độ công nghiệp: xảy ra khi người lao động có kỹ năng (lành nghề) di chuyển từ khu vực công nghiệp này sang khu vực công nghiệp khác hoặc chuyển hẳn ra khỏi khu vực công nghiệp.

Khi nghiên cứu về những yếu tố tác động đến chảy chất xám, tác giả chia ra làm hai nhóm: nhóm "kéo" và nhóm "đẩy".

- Nhóm "đẩy" bao gồm điều kiện sống thấp, tỷ lệ thất nghiệp cao, khủng hoảng tài chính, lương thấp, chính trị bất ổn, thiếu tự do về học thuật, cá nhân,... Những yếu tố này khiến những nhân lực chất lượng cao rời bỏ tổ quốc và tìm kiếm những nơi có điều kiện tốt hơn. 
- Nhóm "kéo" bao gồm các yếu tố có tính chất trái ngược với nhóm "đẩy". Những "miền đất hứa" này thu hút nguồn nhân lực chất lượng cao đến thông qua: thu nhập cao, chất lượng cuộc sống tốt, kinh tế phát triển, môi trường chính trị ổn định, tự do cá nhân và những cơ hội học tập, điều kiện sống tốt, môi trường hỗ trợ cho phát triển công việc và cá nhân. Chính những nhân tố này đã kéo nhân lực chất lượng cao ra khỏi đất nước của họ.

Hiện tượng chảy chất xám được thể hiện dưới nhiều hình thức khác nhau như:

- Những người được đào tạo trong nước, sau đó sang các quốc gia khác làm việc và cống hiến cho các quốc gia đó. Hình thức này được xem xét như một dạng di động xã hội bất lợi cho quốc gia gốc - nơi mà đã đầu tư nuôi dưỡng, đào tạo nhưng lại không được "gặt hái" thành quả.

- Những người đi du học/được cử đi đào tạo nhưng không làm việc, cống hiến cho tổ quốc. Hình thức này được thể hiện dưới hai dạng: du học/được cử đi đào tạo tại một quốc gia rồi ở lại quốc gia đó để làm việc và $\mathrm{du}$ học/được cử đi đào tạo tại nước ngoài nhưng khi quay trở lại tổ quốc lại bỏ nghề, làm những công việc không đúng chuyên môn được đào tạo.

Tuy nhiên cũng có một chiều cạnh khác được nhìn nhận trong vấn đề "chảy chất xám". Thông qua kết quả nghiên cứu gần đây của Dalmeet Singh Chawla đăng trên Tạp chí Nature ngày 4/10/2017 đã chỉ ra rằng những nhà khoa học di động được trích dẫn nhiều hơn $40 \%$ so với các nhà khoa học không di động. Kết quả này được phân tích từ 14 triệu bài báo được công bố trong giai đoạn 2008-2015 của 16 triệu tác giả [7]. Theo kết quả trên thì sự di động góp phần làm tăng cơ hội được trích dẫn cho những nhà khoa học.

\subsection{Chảy chất xám theo quan niệm 4.0}

Thông thường, từ trước đến nay, "chảy chất xám" vẫn được dùng với ý nghĩa tiêu cực và luôn là bài toán khó khiến các quốc gia phải cân nhắc và tính toán. Qua quan điểm truyền thống về chảy chất xám bên trên, chúng ta có thể dễ dàng nhận thấy điều này. "Chảy chất xám" luôn là mối lo thường trực của các quốc gia và là vấn đề nóng trên các diễn đàn.

Tuy nhiên, bản chất của khoa học là một hoạt động toàn cầu, nó có tính "cộng đồng"", do vậy cộng đồng khoa học bắt buộc phải là một hệ mở, trong đó, các nhà khoa học tự do chia sẻ, trao đổi và sáng tạo.

Ngoài những quan điểm thông thường về chảy chất xám gắn liền với hiện tượng di cư, trong bối cảnh toàn cầu hóa và cuộc cách mạng thông tin, chảy chất xám còn được biến thiên thành dạng mới với tên gọi: chảy chất xám tại chỗ (hay chảy chất xám không kèm di cư). Dưới tác động của cuộc cách mạng công nghiệp 4.0 thì loại hình chảy chất xám tại chỗ càng hiện hữu rõ và đem lại những tác động đa chiều hơn. Cùng với đó, xu hướng hội nhập quốc tế và sự phát triển của công nghệ thông tin khiến nguồn nhân lực $\mathrm{KH} \& \mathrm{CN}$ không tránh khỏi dòng chảy này, đặc biệt là nguồn nhân lực KH\&CN chất lượng cao. Nhưng hiện tượng này không được biểu hiện một cách rõ ràng và không dễ để nhận biết. Theo quy luật "cung-cầu" của thị trường lao động, chất xám luôn có nhu cầu và mong muốn được dịch chuyển đến những nơi mà lợi ích được tối đa hóa. Dòng chảy này diễn ra một cách tất yếu và tự nhiên. Khi mà thế giới được ví như "một công trường lao động", người lao động có thể tự do di chuyển để lựa chọn vị trí làm việc, lựa chọn công việc mà mình thích. Tuy nhiên, sự di chuyển này không còn đơn thuần chỉ là $d i$ chuyển về mặt địa lý một cách co học của nhân lực khoa học nữa mà nó đã trở thành sụ chuyển dịch riêng của dòng chất xám.

Dưới khía cạnh các tác động dương tính, có thể thấy hiện tượng chảy chất xám tại chỗ sẽ tạo ra một sự thăng bằng về mặt lực lượng nhân lực khoa học, bù đắp được sự

\footnotetext{
${ }^{1}$ Tính cộng đồng (communalism) là một chuẩn mực trong hoạt động khoa học. Chuẩn mực này quy định rằng tri thức là phải chia sẻ thông qua việc công bố các kết quả nghiên cứu. Xem thêm tại Vũ Cao Đàm (2008), Chuẩn mục và kiểm soát xã hội đối với các chuẩn mục trong hoạt động khoa học. Tạp chí Tia sáng.
} 
thiếu hụt nhân lực khoa học trong các lĩnh vực kinh tế, chính trị, xã hội của đất nước. Trong quá trình tiến hành nghiên cứu nội dung này, tác giả đã có nhiều cơ hội được quan sát và ghi chép cũng như có các cứ liệu để nhận thấy sự thiếu hụt về nhân lực khoa học đặc biệt là nhân lực khoa học có trình độ, chất lượng cao hiện nay. Có những ngành nghề, những lĩnh vực chuyên môn chỉ có một hay một số chuyên gia, nhưng nhu cầu thực tế về giảng dạy, nghiên cứu cũng như tiến hành các công việc có liên quan đến lĩnh vực chuyên môn là rất lớn. Do vậy, hiện tượng làm thêm, tham gia cộng tác với các cơ quan ngoài tổ chức, chảy chất xám tại chỗ diễn ra như một tất yếu của dòng chảy chất xám để bù đắp tự nhiên vào các "lỗ hổng chất xám" đang còn thiếu hụt trong lực lượng lao động. Việc tận dụng chất xám này làm tăng cường hiệu suất chất xám và hiệu suất lao động của quốc gia/thế giới nói chung. Hoặc mặt khác, việc di động không kèm di cư có thể làm tăng cường năng lực chuyên môn khoa học của cá nhân, làm chặt chẽ thêm về mối liên kết hợp tác giữa các đơn vị, khu vực, giữa các quốc gia. Đây cũng có thể là cánh cổng mở ra cơ hội cho nhân lực KH\&CN có thêm tri thức khoa học, cơ hội học hỏi, liên kết, có thêm thu nhập hoặc được thỏa mãn đam mê về khoa học. Về mặt tác động âm tính, hiện tượng này ảnh hưởng đến chât lượng công việc tại cơ quan/quốc gia của nhân lực $K H \& C N$ và làm giảm đi tính hiệu quả của chính sách quản lý nhân lực KH\&CN tại cơ quan/quốc gia đó. Chưa kể, về lâu dài, hiện tượng này sẽ gây ra nhiều tác động về tâm lý hoặc sẽ chuyển sang loại hình di động xã hội kèm di cư nếu tổ chức không có những chính sách đúng đắn, kịp thời.

\section{Yếu tố tác động đến hiện tượng chảy chất xám tại chỗ}

Yếu tố đầu tiên và có vai trò hậu thuẫn đối với việc chảy chất xám tại chỗ đó chính là sự ra đời và phát triển của "công nghệ thông tin". Trong cuốn sách "Thế giới phẳng" của Thomas
L.Friedman, trong 10 nhân tố làm phẳng thế giới được xác định thì yếu tố có vai trò quyết định nhất chính là công nghệ thông tin. Đây là lực đẩy chính khiến trái đất phẳng và tạo ra một sân chơi toàn cầu. Thêm vào đó, nó là tác nhân gián tiếp dẫn đến việc "outsourcing" (thuê ngoài) khi mà chuyên gia không cần phải vượt đại dương xa xôi để đến những miền đất hứa nữa: "Chuyện đó sẽ không bao giờ xảy ra nũa, vì chúng ta đã xây con tàu vuợt đại dương này, được gọi là cáp quang... Trong hàng thâp kỉ bạn phải rời khỏi Ân Độ để trở thành chuyên gia... Bây giờ bạn có thể plug [cắm] vào thế giới tù Ân Độ. Bạn không cần phải đến Yale và không cần phải làm việc cho Goldman Sachs" [8]. Như vậy, câu chuyện di động mới được mở ra là nhà khoa học không cần phải di cư mà vẫn có thể trao đổi chất xám đến các tổ chức khác, quốc gia khác khi chỉ cần có mạng internet. Các quốc gia, các tổ chức cũng không cần phải sở hữu nhân lực, không cần phải có các chính sách nhập cư hấp dẫn nữa mà vẫn có nguồn chất xám chất lượng cao. Internet chính là sợi dây kết nối cung - cầu chất xám và sự kết nối này gần như là "miễn phí" và mang tính "khuyến khích" người sử dụng do vậy chất xám và nơi có nhu cầu có thể thỏa sức kết nối. Chính vì vậy, các thành tựu to lớn của công nghệ thông tin đã và đang tạo ra các luồng di chuyển chất xám không ngừng. Bối cảnh cuộc cách mạng công nghiệp 4.0 đã và đang có tác động mạnh mẽ đến khả năng và hiệu quả kết nối các luồng chất xám giữa các quốc gia, khu vực.

Yếu tố thứ hai, tác động đến chảy chất xám tại chỗ là hội nhập quốc tế và xu thế toàn cầu hóa. $\mathrm{Xu}$ thế toàn cầu hoá và hội nhập kinh tế quốc tế ngày càng gia tắng. Đây vừa là quá trình hợp tác để phát triển vừa là quá trình đấu tranh giữa các nước để bảo vệ lợi ích quốc gia. Để tồn tại và phát triển trong môi trường cạnh tranh ngày càng quyết liệt, những yêu cầu về tăng năng suất lao động, thường xuyên đổi mới và nâng cao chất lượng sản phẩm, đổi mới công nghệ, đổi mới phương thức tổ chức quản lý, đang đặt ra ngày càng gay gắt hơn. Chính vì đó, các quốc gia luôn muốn thu hút luồng chất xám đến quốc gia mình. Hội 
nhập quốc tế cũng mở ra nhiều những điều kiện giao lưu, trao đổi về nguồn nhân lực khiến các quốc gia đều chú trọng và lưu tâm đến vấn đề tạo ra những hố đen để hút chất xám.

Yếu tố thứ ba, theo tác giả chính là việc "lãng phí chất xám". Tại sao vậy? Bên cạnh những lực kéo ở trên như internet, toàn cầu hóa hay hội nhập kinh tế, yếu tố đẩy khiến chất xám chảy tại chỗ chính là sự lãng phí. Khi chất xám không được sử dụng hêt, thì theo lẽ đương nhiên, nó sẽ được tận dụng để phục vụ cho những đơn vị, tổ chức, quốc gia khác. Thậm chí, đến một lúc nào đó, quốc gia - nơi mà chất xám sinh ra, đang sinh sống và đang cống hiến lại chỉ là quốc gia hưởng lượng chất xám dư thừa. Bởi xét đến cùng, việc sử dụng chất xám ở đâu và như thế nào vẫn là quyết định của bản thân nhân lực KH\&CN.

\section{Một số vấn đề đặt ra đối với hiện tượng chảy chất xám tại chỗ ở Việt Nam}

Trong bối cảnh hội nhập quốc tế, Việt Nam đã và đang từng bước tạo cho mình những cơ hội hợp tác phát triển với việc tham gia vào các sân chơi chung của khu vực cũng như của thế giới như WTO, CP TPP, AEC,... Việc tham gia các cộng đồng chung này đem lại nhiều lợi ích, nhiều phương hướng, chiến lược cho việc phát triển nguồn nhân lực $\mathrm{KH} \& \mathrm{CN}$ chất lượng cao nhưng cũng đem lại những mối đe dọa liên quan đến chảy chất xám cho Việt Nam. Chảy chất xám là một điều hiển nhiên cần phải chấp nhận trong bối cảnh hội nhập quốc tế này. Nếu không có những định hướng chính sách kịp thời và đúng đắn, Việt Nam sẽ rơi vào "bẫy" thiếu hụt nguồn nhân lực $\mathrm{KH} \& \mathrm{CN}$ chất lượng cao trong một tương lai không xa ngay cả khi Việt Nam có đủ "số lượng" nhân tài nhưng "chất lượng" lại được tận dụng ở nơi khác.

Hiện nay, hầu hết các chính sách quản lý nguồn nhân lực chất lượng cao của Việt Nam đang chú trọng đến vấn đề thu hút, đào tạo nguồn như Nghị định 87/2014/NĐ-CP, Quyết định 356/2005/QĐ-TTg; Đề án 165,...Tuy nhiên, các chính sách cần chú trọng hơn đến các khía cạnh khác của quản lý nguồn nhân lực KH\&CN chất lượng cao như bồi dưỡng, trọng đãi và sử dụng. Trong thực tế, các chính sách trên chưa phát huy được hiệu quả, vẫn có những bất cập dẫn đến tình trạng một người làm nhiều việc cho nhiều cơ quan tổ chức/quốc gia cùng một lúc. Vậy vấn đề chảy chất xám tại chỗ cần được nhìn nhận và lưu tâm như thế nào?

Trước hết, cần mở rộng khái niệm và nhận thức về "chảy chất xám". Chảy chất xám không đơn thuần là việc di chuyển của nhân lực chất lượng cao mà bản chất của nó phải là việc di chuyển của luồng chất xám. Hiểu như vậy để các nhà quản lý, các nhà nghiên cứu nhìn nhận sâu hơn về vấn đề chảy chất xám trong chính tổ chức, đất nước mình để thấy rằng "giữ hay thu hút" chất xám không quan trọng bằng "sử dụng chất xám" đó như thế nào. Chúng ta cứ mải miết giữ số lượng, thu hút thêm từ bên ngoài mà quên mất đi việc sử dụng lượng chất xám đang có.

Thứ hai, nhìn nhận về chảy chất xám một cách đa chiều hơn. Chảy chất xám hay chảy chất xám tại chỗ đều là những luồng chảy tất yếu trong bối cảnh cuộc cách mạng công nghiệp 4.0 khi mà việc "sản xuất và tiểu dùng hiệu quả hơn so với nhũng gì thể hiện qua các chỉ số kinh tế "[9] thì nguồn chất xám cũng sẽ không nằm ngoài nguyên tắc vận hành đó. Chất xám cần được "tiêu dùng" một cách hiệu quả hơn.

Thứ ba, triết lý của các chính sách hiện nay chính là đánh giá chất lượng nguồn nhân lực $\mathrm{KH} \& \mathrm{CN}$ chất lượng cao thông qua lực lượng lao động tại chỗ và các đóng góp hiện tại của họ đối với tổ chức, đơn vị. Cùng với đó, các biện pháp quản lý hành chính với nguồn nhân lực $\mathrm{KH} \& \mathrm{CN}$ chất lượng cao làm gia tăng rào cản tâm lý, gia tăng lực đẩy cho việc di động của nhân lực. Trong bối cảnh cuộc cách mạng công nghiệp 4.0, triết lý quản lý lao động tại chỗ cũng không còn phù hợp nữa, mà thay vào đó cần chú trọng hơn đến việc sử dụng chất xám, đánh giá đóng góp và hiệu năng của chất xám, để chất xám tại Việt Nam không còn bị ví như "bò sữa", được đầu tư, nuôi dưỡng tại Việt Nam nhưng quốc gia khác lại được hưởng lợi. 
Thứ tư, thay đổi triết lý quản lý di dộng xã hội nguồn nhân lực KH\&CN chất lượng cao từ việc lo ngại "chảy chất xám" sang vấn đề về "tuần hoàn chất xám". Việc thay đổi này không phải là tâm lý $\mathrm{AQ}$, "bình mới rượu cũ" mà là việc mở rộng sự nhìn nhận về chảy chất xám. Chảy chất xám đã trở thành một lẽ tất yếu, không thể loại bỏ trong bối cảnh cuộc cách mạng 4.0, các quốc gia đều phải học cách chung sống, hạn chế những tác hại của việc chảy chất xám gây ra và tận dụng những lợi thế mà chảy chất xám đem lại như trình độ/năng lực của nhân lực, mối liên kết, hợp tác quốc tế, khả năng thu hút dự án đầu tư, kiều hối,...Cùng với đó, các quốc gia cũng sẽ có sự nhìn nhận sâu sắc hơn về những điểm yếu, những lỗ hổng trong công tác quản lý nguồn nhân lực chất lượng cao của mình.

\section{Lời cảm ơn}

Bài viết là kết quả nghiên cứu thuộc đề tài "Chính sách quản lý di động xã hội đối với nguồn nhân lực khoa học và công nghệ chất lượng cao trong bối cảnh hội nhập quốc tế" (Mã số KX01.01/16-20) thuộc Chương trình khoa học và công nghệ trọng điểm cấp quốc gia giai đoạn 2016-2020: "Nghiên cứu những vấn đề trọng yếu về khoa học xã hội và nhân văn phục vụ phát triển kinh tế xã hội” - Mã số KX.01/16-20.

\section{Tài liệu tham khảo}

[1] Brandi Maria Carolina (2004). The history of brain drain. https://www.researchgate.net/publication/2907795 60_The_history_of_brain_drain

[2] https://cyberleninka.ru/article/n/the-problems-ofbrain-drain-in-russia-and-member-states-of-theeurasian-economic-union-eaeu

[3] https://www.merriam-webster.com

[4] https://www.worldatlas.com/articles/what-isbrain-drain.html

[5] Collins English Dictionary. Copyright (C) HarperCollins Publishers

[6] https://www.investopedia.com/terms/b/brain_drain.a $\mathrm{sp}$

[7] Dalmeet Singh Chawla (2017), Migrating researchers are cited the most, study finds, http://www.sciencemag.org/news/2017/10/migrating -researchers-are-cited-most-study-finds

[8] Thomas L.Friedman, Thế giới phẳng, bản dịch của Nguyễn Quang A, Cao Việt Dũng, Nguyễn Tiên Phong, trang 105.

[9] Klaus Schwab (2018), Cách mạng công nghiệp lần thứ tư, Bộ Ngoại giao dịch, Nxb Chính trị quốc gia, trang 63 .

\title{
Brain Drain in the Context of the Fourth Industrial Revolution
}

\author{
Dao Thanh Truong, Nguyen Thi Ngoc Anh \\ VNU University of Social Sciences and Humanities, 336 Nguyen Trai, Hanoi, Vietnam
}

\begin{abstract}
Although brain drain is not a new problem, it has always been a hot issue of the world. In the context of the Fourth Industrial Revolution, brain drain needs to be more rigorously investigated. Brain drain is a complex issue, causing much debate in relation to its negative, positive and peripheral effects. From a traditional point of view, brain drain is a dangerous phenomenon, a social mobility of high quality human resources. Moreover, in the new context, this phenomenon manifests its other latent forms which require more attention from researchers and managers. This
\end{abstract}


paper looks at "brain drain" from a traditional point of view and also from the Fourth Industrial Revolution's perspective. Accordingly, the paper analyzes the factors influencing the internal brain drain and proposes some issues for consideration in the making of policies for managing social mobility of Vietnam's high quality S\&T human resources in the new context.

Keywords: Brain drain, the Fourth Industrial Revolution, social mobility 